\title{
AGRICULTURA FAMILIAR, MERCADO E AGROECOLOGIA: CABEM TODOS NA MESMA CESTA?
}

\author{
ANTUNES JUNIOR, Wolney Felippe ${ }^{1}$ \\ SOARES, Diego Ruiz ${ }^{2}$ \\ SILVA, Bruna Aparecida ${ }^{3}$ \\ MARJOTTA-MAISTRO, Marta Cristina ${ }^{4}$ \\ MONTEBELLO, Adriana Estela Sanjuan ${ }^{5}$
}

\begin{abstract}
RESUMO: Os mercados, para a agricultura familiar, são estratégias historicamente requisitadas. Cabe, no entanto, questionar que tipos de mercados e quais são aqueles condizentes com as suas dinâmicas e suas especificidades. Por isso, os debates relacionados aos canais curtos de comercialização e às vendas diretas assumiram, atualmente, uma agenda central na construção de estratégias sustentáveis e de maior autonomia para a agricultura familiar. Diante disso, este trabalho tem como objetivo geral discutir o potencial das entregas de cestas como um mercado compatível com a agricultura familiar, capaz de aproximar consumidor e produtor, bem como a contribuição da agroecologia neste processo. Especificamente, este trabalho apresenta as distinções de mercado dentro da agricultura familiar, assim como verificar, na literatura, as experiências com o mercado de cestas, a fim de discutir suas vantagens e desvantagens. Para isso, foram realizadas revisões bibliográficas e utilizado o método de análise denominado FOFA (Forças, Oportunidades, Fraquezas e Ameaças). Entre os fatores positivos, as cestas ampliam a garantia de compra e venda o que aprimora o planejamento de plantio e colheita. No que se referem às questões negativas, destacam-se a limitação de mão-de-obra e a não compreensão, por parte dos consumidores, da sazonalidade na produção agrícola. Como conclusão, este trabalho indica que a entrega de cestas estreita a relação entre produtor e consumidor, porém, demanda de ambos os atores a capacidade de compreender suas diferentes perspectivas e de fazer as mediações necessárias. Aponta-se, também, que a agroecologia pode ser o referencial prático, teórico e político para esse processo.
\end{abstract}

Palavras-chave: Mercado de proximidade. Sistema agroalimentar. Cestas agroecológicas.

SUMMARY: Markets for family farming are historically required strategies. It is, however, necessary to question what types of markets and which ones are consistent with their dynamics and their specificities. Therefore, the debates related to the short channels of commercialization and direct sales have now assumed a central agenda in the construction of sustainable strategies and greater autonomy for family farming. In view of this, this work has as general objective to discuss the potential of deliveries of fresh food boxes as a market compatible with family agriculture, able to approach consumer and producer, as well as the contribution of agroecology in this process. We intend to present the market distinctions within the familiar agriculture as well as to verify, within the literature, the experiences with the market of boxes, in order to discuss its advantages and disadvantages. For this, bibliographic reviews and the method of SWOT (Strengths, Weaknesses, Opportunities, Threats) analysis were performed. Among the positive factors, boxes increase the purchase and sale guarantee, which improves planting and harvest planning. Concerning the negative issues, mention should be made of the limitation of labor and the lack of understanding by consumers of seasonality in agricultural production. We concluded that the boxes delivery approaches the producerconsumer relationship, however, demands from both actors the ability to understand the different perspectives and to make the necessary mediations. It is also pointed out that the agroecology can be the background for this process.

\footnotetext{
${ }^{1}$ Engenheiro da madeira, mestrando em Agroecologia e Desenvolvimento Rural - Universidade Federal de São Carlos - UFSCar - Araras/SP; wolney.antunes@gmail.com

${ }^{2}$ Engenheiro Ambiental, mestrando em Agroecologia e Desenvolvimento Rural - Universidade Federal de São Carlos - UFSCar - Araras/SP; diego.soares@usp.br

${ }^{3}$ Agroecóloga, mestranda em Agroecologia e Desenvolvimento Rural - Universidade Federal de São Carlos UFSCar - Araras/SP; brunasilva_ccaufscar@hotmail.com

${ }^{4}$ Docente Associada; Centro de Ciências Agrárias, Universidade Federal de São Carlos - UFSCar - Araras/SP; marjotta@ufscar.br

${ }^{5}$ Docente Adjunta; Centro de Ciências Agrárias, Universidade Federal de São Carlos - UFSCar - Araras/SP; adrianaesm@ufscar.br
} 
Keywords: Proximity market. Agrifood system. Agroecological baskets.

\section{INTRODUÇÃO}

A categoria social dos agricultores familiares, enquanto esta nomenclatura, data de meados dos anos 1990, resultado de uma construção coletiva entre o sindicalismo rural, os movimentos sociais, a academia e o Estado. No entanto, a sua existência, bem como a sua importância, precedem qualquer terminologia, seja a de "pequena agricultura" ou a de "pequenos produtores". As unidades de produção com base familiar, de acordo com as contribuições de Alexander Chayanov, antecedem o capitalismo, resistiram à sua introdução no campo e permaneceram se reproduzindo socialmente (WANDERLEY, 2008; ABRAMOVAY, 2012). No contexto brasileiro, pesquisadores vêm estabelecendo, desde a década de 1980, recortes e parâmetros sobre dados de censos agropecuários a fim de traçar uma tipologia e compreender melhor esses atores sociais (KAGEYAMA; BERGAMASCO, 1989; KAGEYAMA et al, 2006).

A agricultura familiar, de modo geral, se distingue da agricultura patronal pelos próprios agricultores e seus familiares desempenharem os esforços físicos e mentais do trabalho. Ademais, é numa decisão interna, de acordo com as necessidades da família, que se estabelece o balanço entre trabalho, produção e consumo (WANDERLEY, 2003; 2008; ABRAMOVAY, 2012). Cabe ressaltar, porém, que os agricultores familiares não são um grupo social estático e homogêneo, pelo contrário, são diversos e, para cada contexto, constroem suas especificidades. Neste sentido, no Brasil, além das definições trazidas pela sociologia e antropologia rural, há a definição operacional de agricultura familiar - Lei $\mathrm{n}^{\circ}$ 11.326/2006 (BRASIL, 2006) - que estabelece critérios para a participação em políticas públicas. Para os anseios deste trabalho enquadra-se a definição de Schneider (2016), que a apresenta como unidades de produção e trabalho, da qual os agricultores retiram o essencial para a reprodução da família e, também, o essencial para vender, trocar e/ou acumular.

A partir dessas conceitualizações e adotando os agricultores familiares como atores historicamente inseridos à sociedade, com diversas interações e, entre elas, o mercado, tem-se as seguintes reflexões: o que são mercados? Quais mercados mais se aproximam da lógica da agricultura familiar?

Diante do impasse em que, por um lado, o mercado faz parte do imaginário do agricultor familiar e, por outro, ele pode resultar em sua dependência e baixa autonomia, surgem anseios por mercados que atendam às demandas da agricultura familiar e que contribuam para o seu fortalecimento. Como exemplo, os mercados socialmente construídos, de venda direta, de relação justa e de proximidade entre produtor e consumidor, tal qual a entrega de cestas ${ }^{6}$.

Para auxiliar na resolução deste problema, a agroecologia - enquanto enfoque científico (CAPORAL; COSTABEBER, 2002) e práticas endógenas (SEVILLA-GUZMÁN, 2001) - surge como um processo de retomada da autonomia dos agricultores familiares, que contribui para o desenho de agroecossistemas sustentáveis e na reflexão acerca das relações inerentes ao universo dos agricultores, contribuindo de maneira pertinente na construção de mercados compatíveis com a lógica da agricultura familiar.

Assim, o objetivo geral deste trabalho é discutir o potencial das entregas de cestas como um mercado compatível com a agricultura familiar, capaz de aproximar consumidor e produtor, bem como a contribuição da agroecologia na construção desse mercado. Especificamente, este trabalho pretende

\footnotetext{
${ }^{6}$ As entregas de cestas, neste trabalho, serão definidas como vendas diretas de conjuntos de pequenas e variadas porções de hortifrutícolas e/ou produtos minimamente processados oriundos do trabalho da agricultura familiar. 
apresentar as distinções de mercado dentro da agricultura familiar assim como verificar, dentro da literatura, as experiências com o mercado de cestas, a fim de discutir suas vantagens e desvantagens.

\section{METODOLOGIA E REFERENCIAL TEÓRICO}

Este artigo, ao propor uma discussão teórica e reflexiva, reúne conceitualizações e informações acerca da agroecologia, dos mercados e da agricultura familiar, que formam a temática do trabalho. Para isso, foram realizadas revisões bibliográficas em trabalhos teóricos e em estudos de caso que investigaram os mercados acessados pela agricultura familiar. No levantamento da literatura, os olhares se voltaram para os mercados de venda direta, no qual se enquadra a entrega de cestas. Tais informações foram sistematizadas em dois tópicos: "Mercado e Agricultura Familiar" e "Mercados de Cestas".

A partir dessa sistematização foi construída a discussão sobre as vantagens e desvantagens do mercado de cestas, a qual foi destinada à seção "Agroecologia, Mercado e Agricultura Familiar: Cabem todos na mesma cesta?". Utilizou-se nesta etapa o método de análise SWOT (FOFA, em português), baseando-se nos trabalhos de Oliveira et al (2015) e de Nunes (2017). Nesta análise são levantadas as Forças, as Oportunidades, as Fraquezas e as Ameaças do objeto de estudo, sendo as fraquezas e as forças remetentes aos fatores internos do objeto de análise, enquanto as oportunidades e as ameaças são relacionadas aos fatores externos (KOTLER; KELLER, 2007). Por ser indicado para avaliações de cenários e para elaborações de projetos, este método dialoga com a proposta do trabalho e permite uma análise estratégica acerca do objeto de estudo. Ademais, a sua construção se dá sob uma dinâmica participativa, propensa às discussões e reflexões, o que amplia a consistência de seus indicadores.

\section{RESULTADO E DISCUSSÃO}

\section{Mercado e Agricultura Familiar}

A agricultura e o espaço rural, enquanto realidades históricas, estão em constantes transformações. Entretanto, a Revolução Verde intensificou e orientou uma série dessas modificações no campo, por exemplo: a concentração fundiária e de riquezas; a exploração do trabalho; exploração do meio natural acima de sua capacidade; e a intensificação do êxodo rural, resultando em desigualdades de oportunidades, sejam elas de acesso a créditos, de produção, escoamento e acesso a mercados (ESTEVAM; SALVARO; BUSARELLO, 2015).

Em um contexto de globalização, Cravioti (2013) aponta para mudanças significativas nos sistemas agroalimentares, os quais atuam a partir de oligopólios, em que a lógica preponderante se dá pela concentração de corporações fornecedoras de insumos, sementes, de máquinas e equipamentos. $\mathrm{O}$ autor aborda ainda as mudanças ocorridas no modelo de comercialização dos produtos agrícolas, que ocorrem por meio de grandes centros de vendas e de relações verticais ao longo da cadeia produtiva.

A fim de discutir este cenário - que tende a se consolidar em quanto modelo hegemônico - e propor alternativas, é importante compreender as diferentes conformações de mercado. Como bem colocado por Plein e Filippi (2011), Schneider e Ferrari (2015) e Schneider (2016), uma contribuição original e importante para o panorama geral das tipologias de mercado, nas quais os agricultores familiares podem estar inseridos, é dada por Wilkinson (2008) e apresentada na Tabela 1.

De acordo com Wilkinson (2008), e reforçado por Silva et al (2015), existem pelo menos quatro formas de acesso aos mercados e aos meios de escoamento da produção pelos agricultores, a saber: a) acesso direto, sobretudo associado aos mercados locais (informais); b) por intermédio de atravessadores; 
c) integração com a agroindústria; e d) compras por parte do poder público (mercados governamentais).

Schneider (2016), baseando-se em Wilkinson (2008), também avaliou as formas de escoamento da produção. $\mathrm{O}$ autor acrescentou, ainda, as categorias de agricultores e os aspectos como as distinções entre os mercados, a natureza das trocas, as formas de regulação e os canais de comercialização.

Tabela 1: Tipologias de mercado para a agricultura familiar.

\begin{tabular}{ccc}
\hline Mercado & Perfil & Desafios \\
\hline Commodities & $\begin{array}{c}\text { Velhos e novos mercados locais e a } \\
\text { distância }\end{array}$ & $\begin{array}{c}\text { Padronização, Legislação, } \\
\text { Qualidade mínima e Escala }\end{array}$ \\
\hline $\begin{array}{c}\text { Especialidades } \\
\text { (de nicho) }\end{array}$ & $\begin{array}{c}\text { Discriminado por grau de associação } \\
\text { com a localidade/tradição }\end{array}$ & Concorrência de novos integrantes \\
\hline Orgânicos & $\begin{array}{c}\text { Grau de associação à saúde e/ou a um } \\
\text { modo específico de produção }\end{array}$ & Certificação, Escala, Pesquisa \\
\hline Artesanais & Denominação de origem ou não & $\begin{array}{c}\text { Qualidade, Normas técnicas, } \\
\text { Autenticidade, Ação coletiva }\end{array}$ \\
\hline Solidários & $\begin{array}{c}\text { Identificação ou não com a agricultura } \\
\text { familiar, Mercados de alta e baixa renda }\end{array}$ & Escala, Variabilidade, Qualidade \\
\hline Institucionais & Licitaçães, Oferta para varejo & Qualidade, Variabilidade, Escala \\
\hline
\end{tabular}

Fonte: Wilkinson (2008).

Nos últimos anos, no Brasil, grande importância tem sido conferida aos mercados institucionais, como é o caso do Programa de Aquisição de Alimentos - PAA do governo federal (GRISA; SCHNEIDER, 2014; DOS ANJOS; BECKER, 2014). Contudo, será dado maior destaque aos mercados de proximidade e locais/territoriais nas linhas a seguir, uma vez que, para os agricultores familiares, foco deste estudo, tais mercados podem ser promissores e oferecerem possibilidades de absorção das potencialidades intrínsecas às características da produção familiar.

Mercados de proximidade, como desenvolvido por Schneider (2016), são mercados socialmente construídos, nos quais as trocas envolvem, para além da ideia de lucro, relações sociais de reciprocidade e interconhecimento, certa autonomia dos agricultores e, de maneira geral, uma escala local de realização. Vendas diretas do tipo "face a face" ou "porta a porta" são exemplos de mecanismos deste mercado.

Tendendo à mercantilização, os mercados locais ou territoriais ainda abarcam características dos mercados de proximidade, passando a coexistir com outros dispositivos orientados pela oferta e demanda, como são os preços e a concorrência. Sua principal distinção dos mercados de proximidade está na não obrigatoriedade do processo de distribuição e venda dos produtos serem realizados pelo produtor, além do locus de atuação destes canais não estarem ligados a um local específico (SCHNEIDER, 2016).

Diante de um modelo produtivista, global e interligado, é posta para a agricultura familiar certa vulnerabilidade e dependência econômica e social. Como apontado por Nierdele (2009), são inúmeras as experiências inovadoras que envolvem dinâmicas de desenvolvimento de caráter endógeno e territorial. Reconhecidas estas experiências, tem-se discutido, em diferentes âmbitos, suas consequências para o desenvolvimento rural e para a reprodução social dos agricultores familiares.

Se os mercados convencionais são muitas vezes relacionados às cadeias globais de commodities, comandados por corporações transnacionais isentas de vínculos com as localidades, os mercados 
alternativos, por sua vez, estão associados às esferas locais e com relações diretas entre compradores e vendedores. Esses mercados se inserem na lógica de cadeias curtas, com capacidade de ressocializar e (re)espacializar os alimentos, construindo relações socioculturais enraizadas (embedded), conectando localidade, tradição, origem, natureza e modo de produção (NIERDELE, 2009), e possibilitando uma construção mútua de relações de confiança (SCARABELOT; SCHNEIDER, 2012).

Renting et al. (2003), em um estudo sobre o desenvolvimento e ocorrência de redes ou cadeias alternativas de alimentos na Europa, apresentam duas perspectivas de análise das cadeias curtas (short food supply chains - SFSC): a) acerca dos mecanismos de alcance espaço-temporais destas cadeias; b) em relação às características conceituais das cadeias. Compilados destas perspectivas são apresentados nas Tabelas 2 e 3 .

Entre os mecanismos de alcance espaço-temporais, a primeira categoria se refere às interações diretas entre produtores e consumidores, que, muitas vezes, ocorrem na forma de vendas diretas. A categoria seguinte se baseia nas relações de proximidade, mas que se estende a maiores distâncias no tempo e espaço, necessitando de estruturas e arranjos de maior complexidade. Na terceira categoria os produtos são exportados e absorvidos por consumidores distantes do local de produção, porém, preservando seus valores, sejam eles de qualidade ou confiança, associados à localidade de produção. 
Tabela 2: Mecanismos de alcance espaço-temporais das cadeias curtas agroalimentares.

\begin{tabular}{lll}
\hline Face-a-face & Proximidade espacial & Relações estendidas \\
\hline Lojas de produtos agrícolas; Comercialização na & Grupos de lojas de produtos agrícolas; Marcas Certificações; Codificação da \\
propriedade; Vendas na beira da estrada; Colheita & regionais; Cooperativas consumidoras; Comunidade produção (controle); Reputação/ \\
pelos consumidores; Entrega em domicílio; Entrega & que sustenta a agricultura (CSA); Rotas Temáticas - confiança. \\
por encomenda (venda pela internet e entrega por & turismo rural (articulação com o espaço); Eventos \\
encomenda); Montagem de caixas (ou cestas). & $\begin{array}{l}\text { especiais e feiras (articulação no tempo); Lojas locais, } \\
\text { restaurantes e empresas de turismo; Varejistas }\end{array}$ & \\
& especializados; Abastecimento de instituições. & \\
&
\end{tabular}

Fonte: Renting et al., 2003.

Tabela 3: Visões conceituais acerca das cadeias curtas agroalimentares.

Características regionais ou artesanais principais (associadas ao local de produção ou ao produtor)

Designação de origem; Produtos agrícolas ou artesanais, típicos, Orgânicos; Integrados; Naturais; Saudáveis e seguros; Criação animal em tradicionais e especialidades; Produzidos dentro da propriedade; liberdade (bem estar); Alimentos não-transgênicos.

Relações fair trade

\section{Características ecológicas ou naturais principais (associadas aos} bioprocessos)

Fonte: Renting et al., 2003. 
No que tange às visões conceituais das cadeias curtas, as características regionais ou artesanais apresentam relações entre atributos de qualidade do produto e de seu produtor e/ou local de produção, em que aspectos específicos, como a região ou processo produtivo, são cruciais para sua diferenciação em relação aos produtos convencionais. Já as características ecológicas ou naturais se apresentam relacionadas aos processos (e modelos) de produção e produtos resultantes, onde a demanda por alimentos com tais valores vem crescendo, tanto pela preocupação com a saúde dos consumidores quanto pela consciência ambiental.

Uma vez colocadas quais as possibilidades de mercados para a agricultura familiar, indaga-se o que ela pode oferecer dentro destes espaços: qual seu diferencial perante uma modelo altamente tecnicista, dependente de pacotes tecnológicos, com alta capacidade de produção e de distribuição?

Como bem observado por Buainain (2006), a capacidade de sobrevivência da agricultura familiar frente a um quadro de competitividade agroindustrial de alta complexidade - se dá, justamente, pela sua produção de base familiar. Essa essência familiar (que abrange a gestão e a força de trabalho) é capaz, inclusive, de reduzir ou neutralizar as desvantagens associadas aos recursos e às escalas de produção.

Uma das dificuldades da agricultura familiar reside no acesso aos mercados parciais e diversificados, que sejam adaptados às suas características socioeconômicas, fundadas no trabalho familiar e na fusão entre unidade doméstica e unidade produtiva (SABOURIN, 2014). Buainain (2006) destaca que aspectos referentes ao grau de especialização e inserção no mercado são cruciais para compreender as perspectivas de sustentabilidade e de evolução dos agricultores familiares, atentando-se para as transformações e tendências observadas na sociedade e os mercados que podem abrir novos espaços competitivos para a agricultura familiar.

Os impactos ambientais oriundos das atividades agropecuárias têm sido motivo de preocupação cada vez maior por toda a sociedade. Os reflexos das relações entre o meio ambiente e o modelo de agricultura convencional - ver Gliessman (2000) e Caporal (2009) - resultam na concentração da propriedade da terra, na redução da agricultura familiar e da importância dos saberes tradicionais nas práticas agrícolas, assim como na redefinição da participação de parte da família na operação de unidades agrícolas (BUAINAIN, 2006). A lacuna aberta pelo questionamento desse modelo de produção pode ser explorada pela agricultura familiar.

Outra mudança recente está na virada de qualidade (quality turn), assim chamada por Goodman (2003), caracterizada pela valorização de produtos alimentares de qualidade diferenciada por consumidores cada vez mais reflexivos e informados, os quais procuram por alimentos funcionais, saudáveis, com sabor, qualidade, cor e tamanhos específicos (CRUZ; SCHNEIDER, 2010). Para Goodman (2003), essa virada de qualidade está associada ao aumento da quantidade de redes agroalimentares alternativas - Alternative Agrofood Networks (AAFNs) - operantes paralelamente e às margens dos complexos agroalimentares predominantes, sinalizando proximidades ao espaço local, às práticas alimentares alternativas e enraizadas socialmente.

Apesar da produção e do consumo de alimentos industrializados, ou ultraprocessados, serem hegemônicos na grande maioria dos países, os alimentos mais saudáveis e de qualidade diferenciada apresentam demandas crescentes (SCHNEIDER; FERRARI, 2015), abrindo espaços oportunos para a produção agrícola familiar, tanto pela qualidade conferida ao alimento quanto à confiabilidade que a ele pode ser impressa e requisitada pelos consumidores (BUAINAIN, 2006). Essas demandas contribuem, inclusive, para uma produção pautada em agroecossistemas sustentáveis, de base agroecológica, que possibilitam uma melhor qualidade ao produto, às condições de trabalho do produtor, bem como uma maior independência de fatores/insumos externos, conferindo soberania aos agricultores e melhorias progressivas na qualidade de suas terras. 
O diálogo entre o que e como vender é fundamental para o desenvolvimento e sobrevivência da agricultura familiar. Como observado por Wanderley (1996), a agricultura familiar, ao se reproduzir nas sociedades modernas, deve se adaptar ao contexto socioeconômico, impondo modificações em suas formas de produção e reprodução social tradicionais.

São inúmeras possibilidades e espaços a serem ocupados e apropriados pela produção familiar, sobretudo em um momento que, frente a um cenário de desconfiança quanto à qualidade dos alimentos e à sustentabilidade ambiental da produção, amplia-se a busca pela proximidade entre produtor e consumidor. A construção de mecanismos de mercados de proximidade, ou cadeias curtas, oferecem oportunidades e vantagens aos produtores e aos consumidores.

\section{Mercado de Cestas}

Cabe nesta seção, antes de iniciar a apresentação sobre mercado de cestas, propor uma definição mais detalhada para esta estratégia de mercado. Na literatura ainda não há uma terminologia e um conceito específicos para tal, o que pode ser explicado devido à sua origem social e não acadêmica, ou seja, por ter sido inicialmente utilizado entre os agricultores familiares, cooperativas, associações e consumidores e não ter partido, propriamente, de uma definição da academia.

Neste trabalho o termo adotado será o de "Mercado de cestas". Usando a expressão de Goodman et al (2012) e de Darolt et al (2016), o mercado de cestas se enquadra nas "Redes Alimentares Alternativas", as quais são baseadas na cooperação e na parceria entre os atores sociais envolvidos no processo, por exemplo, produtores e consumidores. Essas redes possuem como características os circuitos curtos de comercialização, a dinamização de territórios, bem como um maior apelo aos produtos ditos sustentáveis, ecológicos e de identidade (PICOLOTTO; BREMM, 2016).

O funcionamento do mercado de cestas varia de acordo com os diferentes contextos e com as diferentes dinâmicas vivenciadas pelos agricultores e consumidores, mas, em geral, seguem uma ideia parelha. Basicamente, este mercado se constrói da seguinte maneira: o produtor, que pode ser o agricultor familiar individualmente ou organizado em cooperativas e associações, diversifica sua produção e a organiza em cestas $^{7}$, as quais são oferecidas aos consumidores (comunidade local, moradores urbanos, munícipes em geral) com uma certa periodicidade (semanal, quinzenal ou mensal); as ofertas das cestas podem ser via aplicativos de mensagens, páginas de redes sociais, telefonemas, contatos em feiras locais, entre outros meios; já as entregas podem ser agendadas em um local fixo ou diretamente nas residências dos consumidores.

As cestas têm apresentado, nos últimos anos, certo destaque no universo da agricultura familiar e, também, no de consumidores engajados em alimentação diversificada e saudável. Ademais, Oliveira e Marjotta-Maistro (2016) relatam que o interesse do consumidor em cestas tem crescido, entre outros motivos, em função da comodidade que esse modelo oferece, além de se apresentar como uma alternativa entre a feira e o supermercado. Neste sentido, as cestas são alternativas aos processos de comercialização vigentes, tais como os vinculados às redes de atacado e varejo, apresentando-se como circuitos curtos de comercialização e dinamizadores de economias locais. (FONSECA, 2009).

Os circuitos curtos de comercialização, entre eles o mercado de cestas, são alternativas importantes aos mercados convencionais e integrados ao sistema agroalimentar corporativo, de modo que são estratégias inovadoras, melhores adaptadas à lógica da agricultura familiar e aos diferentes contextos em que ela se insere. Nesse sentido, o mercado de cestas apresenta proximidade com a agroecologia e dialoga com seus princípios, isto é, com os princípios da autonomia, da solidariedade, da segurança e soberania alimentar, da justiça social, dos saberes populares e da aproximação entre quem produz e

\footnotetext{
${ }^{7}$ A palavra "cesta" é usada como uma alegoria, ou seja, como uma simbologia para o formato de entrega dos produtos, que podem ser organizados em caixas, sacolas, etc.
}

Nucleus,v.16,n.2,out.2019 
quem consome alimentos (DAROLT et al, 2016).

Ao realizar uma pesquisa com agricultores familiares no semiárido nordestino, Nunes et al (2018) constataram que, mesmo diante de impasses técnicos-produtivos, os agricultores eram propensos às inovações e experimentações de novas práticas agrícolas, sobretudo as de base agroecológica. Esse caráter experimentador e inovador, pertencente à essência dos agricultores familiares, foi extensamente estudado por Wanderley $(2003$; 2009). Isso permite, por exemplo, deduzir que a demanda por produtos saudáveis e sem adição de agroquímicos, em um ambiente de aproximação entre produtores e consumidores proporcionado pelo mercado de cestas, pode contribuir na transição agroecológica dos agricultores familiares.

Dos Santos e Chalub-Martins (2012) estudaram um grupo de consumo de alimentos agroecológicos em Campinas-SP, com entrega via cestas. Neste trabalho, os autores se referem tanto aos produtores quanto aos consumidores como atores agroecológicos. Ao inserir nos consumidores o adjetivo "agroecológico" evidencia-se a aproximação entre os sujeitos, mostrando que eles pertencem ao mesmo universo e que estão em constantes trocas de experiências. É importante ressaltar que, neste caso, trata-se de um modelo específico de mercado de cestas, que são os grupos de consumo. No caso deste grupo, a iniciativa partiu dos próprios consumidores, os quais se reuniram, discutiram e levantaram os agricultores familiares agroecológicos presentes no local.

Uma vez identificados, os consumidores foram ao encontro dos produtores e iniciaram um processo de negociação. De início, era um grupo reduzido de consumidores e de produtores, no entanto, esse número foi crescendo gradativamente até, no período de publicação da pesquisa, atingir mais de trezentos consumidores e nove famílias produtoras. Neste caso, os pedidos são realizados com auxílio de um software e as cestas são personalizadas para cada consumidor, com entregas semanais em um local fixo e único.

Além de Dos Santos e Chalub-Martins (2012), Defante et al (2014) e Darolt et al (2018) também destacam a aproximação entre produtor-consumidor como uma característica chave no mercado de cestas. Os autores apontam a questão da autonomia no estabelecimento de preços pelos agricultores, o que é decorrente da venda direta.

No entanto, limitações podem surgir na construção desse mercado, seja pelo lado de quem produz, seja pelo lado de quem consome. Como apontam Defante et al (2014), os agricultores familiares apresentam limitações em relação à logística e à disponibilidade de tempo para manejar a produção e, em paralelo, fazer a comercialização, mesmo quando tratam-se de circuitos curtos. Dos Santos e ChalubMartins (2012) ressaltam as dificuldades que tangem à logística e às ferramentas operacionais. Para Darolt et al (2016), o mercado de cestas no Brasil ainda é incipiente e, por mais que esteja ganhando, gradativamente, espaço entre a preferência dos consumidores, o público brasileiro ainda é pouco organizado e pouco engajado socialmente, o que retarda o crescimento deste mercado.

Darolt et al (2016), ao apontarem as dificuldades dos mercados de venda direta, nos quais se encaixam as cestas, trazem elementos na perspectiva dos produtores e dos consumidores. Para os agricultores, as limitações envolvem os riscos de intempéries, a disponibilidade de mão de obra, bem como a capacidade de gerenciar e organizar as diferentes atividades. Já para os consumidores, tratam-se de problemas em relação a regularidade de alguns produtos, devido a sazonalidade.

Diante deste cenário, verifica-se que o mercado de cestas não possuiu um modelo único tampouco padronizado, podendo ser via grupos de consumo, pela iniciativa de agricultores individuais ou por aqueles organizados em associações e cooperativas. Porém, de modo geral, as externalidades desse mercado, assim como as limitações operacionais, parecem ter um comportamento comum. 


\section{Agroecologia, mercado e agricultura familiar: cabem todos na mesma cesta?}

Partindo da discussão apresentada até aqui, observa-se o mercado de cestas como um elemento de aproximação entre os produtores rurais familiares e consumidores, bem como um promotor da transição agroecológica. A partir disso, foi realizada a análise FOFA (Figura 1), com maiores particularizações descritas a seguir.

\section{- Forças}

A principal força deste tipo de mercado é a proximidade estabelecida entre produtor e consumidor, construída por meio do contato direto entre os atores envolvidos, permitindo trocas de experiências e conhecimento de realidades alheias. Nesse processo, é possível conhecer a origem dos produtos e o local de sua produção. Ademais, a agricultura familiar possui certa flexibilidade em remodelar seu sistema e reorientar sua produção, isto é, de acordo com as demandas por produtos específicos (desde que sejam compatíveis com o período de plantio, clima, vegetação, etc.) podem ocorrer a introdução de novos cultivos, além de que frutas e outros vegetais podem ser minimamente processados e transformados em compotas, doces, conservas, etc.

Figura 1: Análise FOFA para Mercado de Cestas.

\begin{tabular}{|c|c|c|}
\hline & Forças & Fraquezas \\
\hline 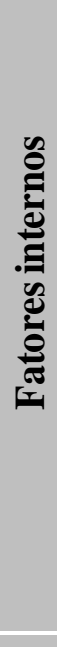 & $\begin{array}{l}\text { Proximidade produtor/consumidor; } \\
\text { Flexibilidade na produção; } \\
\text { Garantia de compra e venda; } \\
\text { Comodidade para os consumidores; } \\
\text { Planejamento de plantio e colheitas; } \\
\text { Diversidade de produtos; } \\
\text { Mudanças de hábitos alimentares; } \\
\text { Conhecimento da origem dos } \\
\text { alimentos; } \\
\text { Organização de produtores } \\
\text { (Associação e Cooperativas); } \\
\text { Maior autonomia para o agricultor; } \\
\text { Redução de resíduos. }\end{array}$ & $\begin{array}{l}\text { Desistência de consumidores; } \\
\text { Possível não aceitação dos itens; } \\
\text { Não compreensão da sazonalidade; } \\
\text { Não compreensão dos imponderáveis } \\
\text { da produção (ex: geadas, secas, } \\
\text { excessos de chuva, pragas e doenças, } \\
\text { etc.); } \\
\text { Limitação de mão-de-obra; } \\
\text { Falta de assistência técnica } \\
\text { diferenciada. }\end{array}$ \\
\hline & Oportunidades & Ameaças \\
\hline 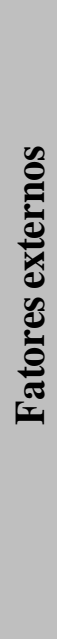 & $\begin{array}{l}\text { Aumento na busca por uma } \\
\text { alimentação saudável e sem } \\
\text { agrotóxicos; } \\
\text { Busca por modelos de produção mais } \\
\text { sustentáveis e socialmente justos; } \\
\text { Aproveitar características regionais, } \\
\text { territoriais e de identidade; } \\
\text { Políticas Públicas } \\
\text { Formação de organizações } \\
\text { (Associações e Cooperativas); } \\
\text { Compartilhamento de aprendizados } \\
\text { (dias de campo, troca de receitas); } \\
\text { Educação ambiental. }\end{array}$ & $\begin{array}{l}\text { Concorrência com redes de } \\
\text { supermercados; } \\
\text { Falsos produtores orgânicos; } \\
\text { Intempéries; } \\
\text { Conjuntura política e econômica; } \\
\text { Apropriação do mercado de cestas } \\
\text { pela agricultura patronal; } \\
\text { Vigilância Sanitária. }\end{array}$ \\
\hline
\end{tabular}

Fonte: Autores (2019). 
Nesse mercado há uma garantia mútua entre produtores e consumidores, ou seja, os agricultores possuem a garantia de um número mínimo de compradores, e os consumidores da oferta de alimentos. Nesse sentido, os produtores podem fazer um melhor planejamento de plantio e colheita, já o público consumidor tem a comodidade de receber alimentos frescos toda semana, quinzena ou mês. Além da garantia, há outros benefícios mútuos, que são a diversidade de produção e as mudanças de hábitos alimentares, quer dizer, ao passo que o produtor diversifica a variedade de alimentos produzidos e oferecidos, os consumidores experimentam novos hábitos alimentares.

Quando os produtores rurais familiares estão organizados em cooperativas ou em associações, a dinâmica de montagem das cestas ocorre de maneira mais fácil, integrada e solidária. Desta maneira, ocorre uma oferta variada de produtos, assim como um menor risco de ausência destes. Sob esta organização, os preços das cestas podem ser mais acessíveis e a busca por novos consumidores mais viável. Por ser uma venda direta, sem interferências de atravessadores e intermediários, o agricultor possui maior autonomia em estabelecer os preços das cestas. Isso implica, também, em preços mais justos aos consumidores. Além da questão dos preços, a entrega direta implica na redução do uso de embalagens e, consequentemente, redução na geração de resíduos.

\section{- Fraquezas}

Se por um lado o mercado de cestas oferece certa garantia nas vendas, por outro, podem ocorrer interrupções no público consumidor, o que acarreta em possíveis perdas da produção, diminuição das vendas (implicando na renda do agricultor) e aumento nos custos operacionais. Por mais que as cestas construam uma relação de proximidade entre produtor e consumidor, a heterogeneidade do público consumidor pode acarretar na não aceitação dos itens oferecidos, na não compreensão da sazonalidade dos produtos e de interferências climáticas, bem como na incompreensão de eventuais adversidades associadas à produção, como quebra de equipamentos, problemas de disponibilidade e fornecimento de insumos, mudas e sementes, resultando em atrasos no plantio e colheita e alterações na composição das cestas. O processo de transição agroecológica pode gerar algumas dificuldades produtivas, que também estão suscetíveis a não compreensão dos consumidores.

Entre as dificuldades internas, destaca-se a limitação quanto à mão de obra. A conciliação entre as atividades de produção agrícola, de vendas, logística e busca por novos consumidores demanda tempo e pessoal treinado. Outra limitação é a ausência de assistência técnica diferenciada e adaptada às realidades da agricultura familiar. Neste sentido, as assistências são, em geral, provenientes de empresas privadas, as quais trabalham com os pacotes tecnológicos convencionais e já consolidados, resultando em um conflito para os agricultores que buscam modos de produção agroecológico.

\section{- Oportunidades}

A busca por uma alimentação variada, saudável e natural, sem resíduos de agroquímicos e sem transgênicos tem se apresentado como uma grande oportunidade de fortalecimento dos mercados de cestas. Em paralelo a isso, há uma demanda crescente entre os consumidores por modelos de produção mais sustentáveis e socialmente justos. Essas demandas (por alimentos e sistemas sustentáveis) contribuem, em certa medida, na busca pela transição agroecológica entre os agricultores familiares.

A proximidade e, consequentemente, a confiança construída entre produtores e consumidores permitem o alcance de novos membros para o mercado, isto é, os familiares, amigos e conhecidos daqueles que já conhecem e acessam esse mercado são públicos novos em potencial. Ademais, as características regionais, territoriais e de identidade são boas oportunidades em angariar novos interessados. Outras externalidades proporcionadas pela aproximação entre produtor-consumidor são as 
vivências compartilhadas entre os atores envolvidos no mercado de cestas, por exemplo, a atividade denominada de dias de campo, trocas de receitas culinárias e trocas culturais, as quais fortalecem o laço entre os sujeitos.

Políticas públicas, por exemplo, o Programa Nacional de Fortalecimento da Agricultura Familiar (PRONAF), na linha Agroecologia, o Programa de Aquisição de Alimentos (PAA) e outros programas de fomento e crédito podem contribuir para que os produtores familiares diversifiquem suas produções, as estruturem e as somem no mercado de cestas. Além disso, as organizações sociais, tais como as associações e cooperativas, podem instigar a novos produtores adentrarem nesse mercado.

\section{- Ameaças}

Entre os fatores externos que ameaçam o funcionamento do mercado de cestas, se destacam as redes de supermercados, que possuem poder de barganha e de estabelecimento de preço, e os atravessadores de produtos orgânicos, os quais implicam em margens de comercialização diferenciadas aos produtores. Somado a isso, a apropriação do mercado de cestas por empresas e agricultores patronais se configuram como um desafio aos agricultores familiares e aos consumidores pertencentes a esse universo. Além do mais, fatos descontextualizados, como a ocorrência de intoxicação alimentar em grupos de consumo, podem desestimular o público consumidor.

\section{CONSIDERAÇÕES FINAIS}

É fato que são múltiplas as relações da agricultura familiar com os mercados, sejam elas por meios que favorecem a sua autonomia e independência, sejam as que vão ao contrário desta direção. Essas relações afetam social, cultural e economicamente a dinâmica das famílias agricultoras. Ter essa compreensão - a partir deste trabalho que, mesmo não esgotando o tema, ampliou a fundamentação do debate - permite um olhar para além da associação da agricultura familiar com a produção capitalista e os aspectos econômicos advindo da mesma no meio rural, isto é, possibilita uma abordagem que contemple todas as dimensões dessas relações e não somente as de cunho econômico.

O mercado de cestas, junto com as feiras e os demais tipos de vendas diretas, são as estratégias que mais condizem com as diferentes realidades e dinâmicas da agricultura familiar. As entregas de cestas, ultimamente, têm ganhado cada vez mais relevância e têm demonstrado ser um mercado que estreita a relação entre produtor e consumidor. Essa aproximação, no entanto, demanda de ambos os atores envolvidos a capacidade de compreender as diferentes perspectivas (a de quem produz e a de quem consome) e de fazer as mediações necessárias. A agroecologia, enquanto uma ciência e prática que reflete sobre a produção e sobre as relações entre produtores e consumidores, pode ser o pano de fundo desse processo.

Retornando à pergunta título deste artigo, a elucidação acerca, sobretudo, dos mercados que a agricultura familiar possui potencial de se destacar, bem como dos possíveis aspectos (Forças, Oportunidades, Fraquezas e Ameaças) intrínsecos ao mercado de cestas, tende para uma resposta positiva, na qual é possível afirmar que, sim, a agroecologia, o mercado e a agricultura familiar cabem na mesma cesta, afinal, a agroecologia só existe e tem sentido se reproduzida na agricultura familiar, a qual, por sua vez, não está desconectada dos mercados. De preferência, mercados que sejam socialmente construídos, compatíveis com a sua lógica e instigadores à transição agroecológica, como demonstra ser o mercado de cestas. 


\section{REFERÊNCIAS}

ABRAMOVAY, R. Paradigmas do capitalismo agrário em questão. São Paulo: Edusp, 2012.

BRASIL. Lei n ${ }^{\circ} 11.26$, de 2006. Estabelece As Diretrizes Para A Formulação da Política Nacional da Agricultura Familiar e Empreendimentos Familiares Rurais. Brasília, 2006.

BUAINAIN, A. M. Agricultura familiar, agroecologia e desenvolvimento sustentável: questões para debate. Brasília: IICA, 2006.

CAPORAL, F. R. Agroecologia: uma nova ciência para apoiar a transição a agriculturas mais sustentáveis. In: CAPORAL, F. R. Agroecologia: uma ciência do campo da complexidade. Brasília, 2009. p. 09-64.

CAPORAL, F. R; COSTABEBER, J. A. Análise multidimensional da sustentabilidade. Agroecologia e desenvolvimento rural sustentável, v. 3, p. 71-84, 2002.

CRAVIOTTI, C. La agricultura familiar en los mercados globales: Articulación horizontal y vertical en la citricultura del Noreste Argentino. In: CONTERATO, M. A. et al. (Org.). Mercados e agricultura familiar: interfaces, conexões e conflitos. Porto Alegre: Via Sapiens, 2013. 358 p.

DA CRUZ, F. T; SCHNEIDER, S. Qualidade dos alimentos, escalas de produção e valorização de produtos tradicionais. Revista Brasileira de Agroecologia, v. 5, n. 2, 2010.

DAROLT, M. R. et al. Redes alimentares alternativas e novas relações produção-consumo na França e no Brasil. Ambiente \& Sociedade, v. 19, n. 2, 2016.

DEFANTE, L. R. et al. Canal de distribuição das hortaliças do assentamento Estrela do Sul. Revista Brasileira de Administração Científica, v. 5, n. 1, p. 200-213, 2014.

DOS ANJOS, F. S; BECKER, C. Agricultura familiar e mercados institucionais: o desenvolvimento como liberdade. Revista Econômica do Nordeste, v. 45, n. 5, p. 107-118, 2014.

DOS SANTOS, F. P; CHALUB-MARTINS, L. Agroecologia, consumo sustentável e aprendizado coletivo no Brasil. Educação e Pesquisa, v. 38, n. 2, p. 469-483, 2012.

ESTEVAM, D. O; SALVARO, G. I. J; BUSARELLO, C. S. Espaços de produção e comercialização da agricultura familiar: as cooperativas descentralizadas do Sul Catarinense. Interações (Campo Grande), v. 16, n. 2, 2015.

FONSECA, M. F. A. C. et al. Agricultura orgânica: regulamentos técnicos para acesso aos mercados dos produtos orgânicos no Brasil. Niterói: PESAGRO-RIO, 2009.

GLIESSMAN, S. R. Agroecologia: processos ecológicos em agricultura sustentável. Porto Alegre: Editora da Universidade - UFRGS, 2000.

GOODMAN, D. The quality 'turn' and alternative food practices: reflections and agenda. Journal of Rural Studies, v.19, ed. 1, p. 1-7, 2003.

GOODMAN, D.; DUPUIS, M.; GOODMAN, M. Alternative Food Networks: Knowl-edge, Practice, and Politics. Nova Iorque: Routledge, 2012.

GRISA, C.; SCHNEIDER, S. Três gerações de políticas públicas para a agricultura familiar e formas de interação entre sociedade e estado no Brasil. Revista de Economia e Sociologia Rural, Brasília, v. 52, p. 125-146, 2014.

KAGEYAMA, A. A; BERGAMASCO, S. M. P. P. A estrutura da produção no campo em 1980. Perspectivas: Revista de Ciências Sociais, 12/13, p.55-72. 1989. 
KAGEYAMA, A. A; BERGAMASCO, S. M. P. P; OLIVEIRA, J. T. A. Uma tipologia dos estabelecimentos agropecuários do Brasil a partir do censo de 2006. Revista de economia e sociologia rural, v. 51, n. 1, p. 105-122, 2013.

KOTLER, P.; KELLER, K. L. Administração de Marketing. São Paulo: Pearson, 2007.

NIEDERLE, P. A. Delimitando as fronteiras entre mercados convencionais e alternativos para a agricultura familiar. Extensão rural, v. 16, p. 5-38, 2009.

NUNES, E. M. et al. Novidades (Novelty) na Agricultura Familiar e sua associação com a agroecologia na produção de hortifrutigranjeiros no Território Sertão do Apodi (RN). REDES: Revista do

Desenvolvimento Regional, v. 23, n. 1, p. 213-236, 2018.

NUNES, P. J. Estratégias de comercialização adotadas por famílias que praticam agrofloresta: um estudo de caso no assentamento Mário Lago, Ribeirão Preto/SP. 2017. 107 f. Dissertação (Mestrado) Curso de Agroecologia e Desenvolvimento Rural, Universidade Federal de São Carlos, Araras, 2017.

OLIVEIRA, B. M. et al. Alimentos orgânicos: cadeia produtiva, políticas públicas e análise SWOT. In: CONGRESSO DA SOCIEDADE BRASILEIRA DE ECONOMIA, ADMINISTRAÇÃO E SOCIOLOGIA RURAL, 53., 2015, João Pessoa. Anais. João Pessoa: Sober, 2015. p. 1 - 17. Disponível em: http://icongresso.itarget.com.br/tra/arquivos/ser.5/1/5329.pdf. Acesso em: 27 nov. 2018.

OLIVEIRA, P. S; MARJOTTA-MAISTRO, M. C. Canais de comercialização de orgânicos: alternativas para os agricultores familiares do leste paulista. Revista Brasileira de Gestão e Desenvolvimento Regional, v. 12, n. 3, 2016.

PICOLOTTO, E. L; BREMM, C. Ecologização na agricultura familiar, feiras e produtos artesanais na região Central do Rio Grande do Sul. Política \& Sociedade, v. 15, p. 104-130, 2016.

PLEIN, C; FILIPPI, E. E. Capitalismo, agricultura familiar e mercados. Redes, v. 16, n. 3, p. 98-121, 2011.

RENTING, H; MARSDEN, T. K.; BANKS, J. Understanding alternative food networks: exploring the role of short food supply chains in rural development. Environment and planning A, v. 35, n. 3, p. 393$411,2003$.

SABOURIN, E. Acesso aos mercados para a agricultura familiar: uma leitura pela reciprocidade e a economia solidária. Revista Econômica do Nordeste, v. 45, n. 5, p. 21-36, 2014.

SCARABELOT, M; SCHNEIDER, S. As cadeias agroalimentares curtas e desenvolvimento local: um estudo de caso no município de Nova Veneza/SC. Revista Faz Ciência, v. 14, n. 19, p. 101, 2012.

SCHNEIDER, S. Mercados e Agricultura Familiar. In: MARQUES, F. C; CONTERATO, M. A; SCHNEIDER, S. Construção de Mercados e Agricultura Familiar: Desafios para o Desenvolvimento Rural. Porto Alegre: Ufrgs, 2016. Cap. 4. p. 93-136.

SCHNEIDER, S; FERRARI, D. L. Cadeias curtas, cooperação e produtos de qualidade na agricultura familiar: o processo de relocalização da produção agroalimentar em Santa Catarina. Organizações Rurais \& Agroindustriais, v. 17, n. 1, 2015.

SEVILLA-GUZMÁN, E. Uma estratégia de sustentabilidade a partir da agroecologia. Agroecologia e Desenvolvimento Rural Sustentável, Porto Alegre, v. 2, n. 1, p. 35-45, 2001.

SILVA, M. G; DIAS, M. M; AMORIM, P. C. G. J. Mudanças organizacionais em empreendimentos de agricultura familiar a partir do acesso ao Programa Nacional de Alimentação Escolar. Revista de Economia e Sociologia Rural, v. 53, n. 2, p. 289-304, 2015. 
WANDERLEY, M. de N. B. Agricultura familiar e campesinato: rupturas e continuidade. Estudos sociedade e agricultura, v. 21, n. Oct, p. 42-61, 2003.

WANDERLEY, M. de N. B. Em busca da modernidade social: uma homenagem a Alexander V. Chayanov. In: Para pensar: outra agricultura. 2 ed. Curitiba: Editora da UFPR, p. 32-56, 2008.

WANDERLEY, M. de N. B. O agricultor familiar no Brasil: um ator social da construção do futuro. Revista Agriculturas: experiências em Agroecologia. RJ: Rio de Janeiro, 2009.

WANDERLEY, M. de N. B. Raízes históricas do campesinato brasileiro. In: TEDESCO, J. C. (org.). Agricultura Familiar Realidades e Perspectivas. 2 ed. Passo Fundo: EDIUPF, Cap. 1, p. 21-55, 1999.

WILKINSON, J. Mercados, redes e valores: o novo mundo da agricultura familiar. Porto Alegre, UFRGS, 2008. 